\title{
A HISTÓRIA E CULTURA AFRICANA EM SOCIOLOGIA: AS RELIGIÕES DE MATRIZ AFRICANA
}

\section{African history and culture in Sociology: the religions African origin}

\author{
Tamara Vieira ${ }^{1}$
}

\begin{abstract}
Resumo: Há mais de quinze anos foi aprovada a obrigatoriedade do ensino de história e cultura africana e afro-brasileira foi aprovada em 2003 (Lei no 10.639) no currículo de todas as disciplinas que compõem a Educação Básica. $O$ que significou $o$ reconhecimento da ausência do negro enquanto produtor de saber e portador de uma história. Assim, nos restringimos ao modo como a história e cultura africana é inserida no ensino de Sociologia, e para isso, nos detemos sobre o modo em que as religiões de matriz africana estão sendo abordados pelos livros didáticos de Sociologia aprovados pelo PNLD 2018. Foi possível identificar que ao abordar as religiões de matiz africana, o debate se restringe ao candomblé e a umbanda, que são observadas no âmbito da diversidade de religiões existentes no Brasil e sua contextualização no âmbito da formação da cultura nacional. Neste sentido, há muito ainda a ser feito para o debate da intolerância religiosa, bem como, do racismo brasileiro.
\end{abstract}

Palavras-chave: Livros didáticos de sociologia. Religiões de matriz africana. Ensino e aprendizagem de sociologia. Lei nº 10.639/03. Educação antirracista.

Abstract: More than fifteen years ago, mandatory teaching of African and AfroBrazilian history and culture was approved in 2003 (Law No. 10,639) in the curriculum of all subjects that make up Basic Education. Which meant the recognition of the absence of black people as a producer of knowledge and bearer of a story. Thus, we restrict ourselves to the way in which African history and culture is inserted in the teaching of Sociology, and for that, we focus on the way in which African religions are being approached by the Sociology textbooks approved by PNLD 2018. It was possible to identify that when addressing religions of African hue, the debate is restricted to candomblé and umbanda, which are observed in the context of the diversity of religions existing in Brazil and their contextualization in the context of the formation of national culture. In this sense, much remains to be done to debate religious intolerance, as well as Brazilian racism.

Keywords: Sociology textbooks. African-based religions. Teaching and learning sociology. Law No. 10,639 / 03. Anti-racist education.

\footnotetext{
1 Mestra em Ciências Sociais pela Universidade Estadual de Londrina (UEL/PR), atuando como professora de Sociologia (SEED/PR). E-mail: proftamaravieira@gmai.com. 


\section{Introdução}

De algum modo tomamos contato com a religião ao longo do nosso processo de socialização, independentemente da fé professada ou se não se professa fé alguma, mesmo assim, sabemos indicar nomes ou identificar símbolos que caracterizam dada religião, consequência da sua extensão na sociedade. Neste sentido, a religião constitui um fenômeno social que interessa à Sociologia enquanto objeto de estudo, e consequentemente, é um tema presente em livros didáticos de Sociologia.

Ao tomarmos a religião enquanto objeto de interesse, devemos frisar que não nos debruçaremos sobre o Ensino Religioso, mas, limitaremos nosso escopo de análise aos conteúdos dos livros didáticos de Sociologia aprovados pelo Edital PNLD 2018 (Programa Nacional do Livro Didático), para uso ao longo do triênio 2018, 2019 e 2020. E, em virtude da amplitude de possibilidades sobre este tema, afunilamos a análise aos conteúdos referentes à história e cultura africana e afro-brasileira, em especial, as religiões de matriz africana.

Pois, a partir desta temática podemos nos voltar a um dos objetivos da Lei $n^{\circ}$ 10.639/2003, a proposição de uma educação antirracista, onde ao entendermos o estigma dos adeptos a tais religiões, não podemos nos furtar ao debate do racismo como sistema de discriminação e violência a tudo que se refere ao africano e afro-brasileiro (critério étnico-racial). Onde, de um lado, elas constituem elemento de distinção e violência, por outro, significam, no caso do candomblé, um mecanismo de preservação da cultura, e consequentemente de humanidade por parte dos cativos africanos e afrobrasileiros, e no caso da umbanda, da reafirmação de uma identidade brasileira.

Assim, observaremos as religiões de matriz africana no espaço dos livros didáticos de Sociologia em uso na Educação Básica tendo como norte metodológico a análise de conteúdo, em consequência de sua possibilidade de descortinamento frente à potência do livro didático no processo de ensino-aprendizagem do educando. E buscamos superar incertezas frentes aos conteúdos de história e cultura africana e afrobrasileira abordados pela disciplina de Sociologia a partir dos livros didáticos.

Neste percurso, a inserção da análise de conteúdo apresenta duas funções: uma função heurística, onde se identifica as informações contidas no corpus selecionado e uma função de administração da prova, quando a análise será orientada a partir de problemas ou hipóteses a serem verificadas no corpus selecionado (BARDIN, 2004). 
Assim, como as religiões de matriz africana, o candomblé e a umbanda estão sendo abordados nos livros didáticos de Sociologia, aprovados pelo PNLD 2018? Para respondermos, partiremos de uma observação panorâmica sobre o processo de inserção da Sociologia como disciplina escolar na Educação Básica, seguida do entendimento, também processual, da obrigatoriedade dos conteúdos de história e cultura africana e afro-brasileira (Lei $n^{\circ} 10.639 / 2003$ ). Por fim, nos detemos à análise dos livros didáticos, nos quais realizamos uma leitura seletiva e restrita a temática de interesse.

\section{Contextualização: Sociologia, um saber escolar}

A participação da Sociologia no currículo escolar brasileiro foi marcada por sua inconstância, expondo o a educação enquanto campo de disputa, vinculada ao processo de desenvolvimento de um sistema de educação nacional (SAVIANI, 1999). Identificamos que a inserção das Ciências Sociais no Brasil se deu por meio da educação escolar (MEUCCI, 2000), a partir de 1882, com a proposição de projeto de Reforma Educacional, o qual sugeria a inserção de Elementos da Sociologia para o Secundário e Fundamentos em Sociologia para a Escola Normal, proposto por Rui Barbosa. O projeto não foi aprovado.

Em 1890, temos uma segunda tentativa, com a aprovação do Decreto $\mathrm{n}^{\circ}$ 981/1890 de Benjamin Constant, o qual propunha reforma ao ensino secundário, e incluía como uma das disciplinas: Sociologia e moral (ENGERROFF, 2017), entretanto, a aprovação do projeto não garantiu sua materialização no currículo escolar. Deste modo, a disciplina passará a constar nas escolas a partir de 1925, com a aprovação do Decreto $n^{\circ}$ 16.732-A, de autoria de João Luís Alves-Rocha Vaz, o mesmo incluía o ensino de Sociologia no Ginasial para aqueles que tinham interesse no curso de Bacharel em Ciências e Letras. A partir de 1928, ocorre sua inclusão também nos programas dos Cursos de Magistério (MEUCCI, 2000). Cabe ressaltar que a partir de diversas especificações, a Sociologia, enquanto conhecimento escolar, sempre esteve presente nos currículos dos cursos de preparação dos profissionais do Magistério.

A obrigatoriedade do ensino de Sociologia foi concomitante ao desenvolvimento do mercado de livros didáticos e a criação de cursos universitários na área de Ciências Sociais na Escola Livre de Sociologia e Política (1933), na Universidade de São Paulo (1934), na Universidade do Distrito Federal (1935) e na Universidade do Paraná (1938) (MEUCCI, 2000). Esse período de permanência da disciplina no currículo foi interrompido em 1942, pela Reforma Gustavo Capanema (Decreto Lei no 4.244/1942), 
que retira a obrigatoriedade da disciplina dos currículos do Ensino Secundário, sendo mantida apenas no Curso Normal Superior.

Após a Reforma Gustavo Capanema (1942) temos um período nebuloso em relação à permanência da Sociologia nos currículos que durará até 2008, quando ela volta a fazer parte do currículo do Ensino Médio, observamos que mesmo sem a obrigatoriedade da disciplina ela continuou nos currículos escolares de forma intermitente. Assim, com a Lei $\mathrm{n}^{\mathrm{o}} 11.684 / 2008$ a Sociologia retorna ao currículo da Educação Básica como disciplina obrigatória, por meio de alteração na Lei de Diretrizes e Bases da Educação Nacional (Lei n ${ }^{\circ}$ 9.394/1996), junto com a disciplina de Filosofia.

E atualmente, com a Reforma do Ensino Médio, nos encontramos em uma situação de instabilidade, pois a Sociologia perde seu caráter de disciplina, passando a ser identificada como “estudos e prática” por meio de Medida Provisória no 746/2016 e convertida na Lei $\mathrm{n}^{\mathrm{o}} 13.415 / 2017$, neste contexto, os conteúdos de Sociologia serão inseridos pelas demais disciplinas de acordo com o que for estipulado pela Base Nacional Comum Curricular (BNCC).

[...] Ainda que pairem incertezas sobre a forma em que estes conteúdos serão tratados e da permanência da sociologia na escola, o edital para a seleção dos novos livros didáticos (PNLD 2018) contemplou esta disciplina, aprovandose novos livros didáticos de sociologia, demonstrando ser o livro didático forte agente legitimador da sociologia na escola (ENGERROFF, 2017, p. 23).

Neste contexto, observamos mudanças também na política de livros didáticos, iniciada na década de 1930, sendo importante no tocante à compra e distribuição, contribuindo no processo de ensino e aprendizagem (Decreto-Lei $\mathrm{n}^{\mathrm{o}} 1.006$, de 30/12/1938). Avançando para o atual contexto, em 2017, a política de livros didáticos passa por mudanças orientadas pelo Decreto $n^{\circ}$ 9.099, onde há a unificação das ações de aquisição e distribuição de livros didáticos e literários, anteriormente contempladas pelo Programa Nacional do Livro Didático (PNLD) e pelo Programa Nacional Biblioteca da Escola (PNBE). Com nova nomenclatura, o Programa Nacional do Livro e do Material Didático - PNLD também teve seu escopo ampliado com a possibilidade de inclusão de outros materiais de apoio à prática educativa para além das obras didáticas e literárias: obras pedagógicas, softwares e jogos educacionais, materiais de reforço e correção de fluxo, materiais de formação e materiais destinados à gestão escolar, entre outros.

Ao entendermos a educação enquanto campo de disputa, não esquecemos que as mudanças ocorridas no currículo escolar e sobre a seleção, compra e distribuição dos 
livros didáticos, estão inseridos no contexto de impeachment da presidente Dilma Rousseff, em 2016, constituiu um divisor de águas frente à política educacional. Por isso, apesar das mudanças apontadas no âmbito da educação, há a necessidade de abordarmos uma normatização que ainda garante o debate sobre a diversidade brasileira, a Lei ${ }^{\circ} 11.645 / 2008$, mais conhecida como Lei $n^{\circ} 10.639 / 2003$.

\begin{abstract}
A referida lei não foi sancionada de um dia para o outro. Ao contrário, antes de ser sancionada, passou por diversos estágios, resultando dos movimentos negros da década de 1970 e do esforço de simpatizantes da causa negra na década de 1980, quando diversos pesquisadores alertaram para a evasão e para o déficit de alunos negros nas escolas em razão, entre outras causas, da ausência de conteúdos afrocêntricos que valorizassem a cultura negra de forma abrangente e positiva [...]. (PEREIRA; SILVA, 2012, p. 2).
\end{abstract}

Sendo assim, pontuamos a Marcha Zumbi dos Palmares contra o Racismo, ocorrida em novembro de 1995, realizada em Brasília. Além da denúncia, se exigiam ações do Estado de combate ao racismo, forçando, a partir de então, o reconhecimento público da existência do racismo no Brasil e incentivando, assim, uma ação mais diretiva no sentido de se discutir o problema e realizar algumas medidas de combate ao racismo (PEREIRA; SILVA, 2012, p. 5). Neste mesmo ano, temos o arquivamento de lei que seria o embrião da Lei $n^{\circ} 10.639$, apresentada à Câmara Federal pelo deputado Paulo Paim, certamente por questões políticas e burocráticas, consideradas na ocasião mais importantes que o contexto das relações étnico-raciais na educação (PEREIRA; SILVA, 2012, p. 6).

Em março de 1999, o Projeto de Lei $n^{\circ}$ 259, formulado pelos então deputados Ben-Hur Ferreira e Esther Grossi referente à obrigatoriedade da temática história e cultura afro-brasileira inicia sua tramitação, processo frisado por Maria do Carmo Xavier e Ana Paula Lacerda Dornelles enquanto ausente "de polêmica e embate políticos [o que] deixa sob suspeita a compreensão dos deputados sobre o sentido e o potencial de uma lei que altera a LDB e provoca alterações na política educacional brasileira" (XAVIER; DORNELLES, 2009, p. 582).

Em 2001, ocorreu a Conferência Mundial contra o Racismo, a Discriminação Racial, a Xenofobia e formas correlatas de Intolerância, em Durban, na África do Sul, o que contribuiu com as discussões sobre racismo e políticas de Ações Afirmativas (PEREZ, 2018). O Projeto de Lei $\mathrm{n}^{\circ} 259$ foi aprovado, sendo modificada sua nomenclatura para Lei $n^{\circ} 10.639$, e foi seguida pela criação da Secretaria Especial de 
Políticas de Promoção da Igualdade Racial (SEPPIR). E, em 2008, houve a revogação da Lei em prol da inclusão dos conteúdos referentes à história e cultura indígena (Lei $\mathrm{n}^{\mathrm{o}}$ 11.645/2008). Vejamos como ficou:

\begin{abstract}
Nos estabelecimentos de ensino fundamental e de ensino médio, públicos e privados, torna-se obrigatório o estudo da história e cultura afro-brasileira e indígena.

$\S 1^{\circ} \mathrm{O}$ conteúdo programático a que se refere este artigo incluirá diversos aspectos da história e da cultura que caracterizam a formação da população brasileira, a partir desses dois grupos étnicos, tais como o estudo da história da África e dos africanos, a luta dos negros e dos povos indígenas no Brasil, a cultura negra e indígena brasileira e o negro e o índio na formação da sociedade nacional, resgatando as suas contribuições nas áreas social, econômica e política, pertinentes à história do Brasil.

$\S 2^{\circ}$ Os conteúdos referentes à história e cultura afro-brasileira e dos povos indígenas brasileiros serão ministrados no âmbito de todo o currículo escolar, em especial nas áreas de educação artística e de literatura e história brasileiras. (BRASIL, 2008).
\end{abstract}

A inserção destes conteúdos em todas as disciplinas que compõem o currículo da Educação Básica pressupõe a formação continuada de professores, bem como a mudança de comportamentos frente ao modo de ensinar, pois além de informar, tais conteúdos objetivam a reeducação para as relações étnico-raciais brasileiras entre negros e brancos, para superação de nossas práticas racistas, a fim de atingirmos uma sociedade orientada pelo respeito ao diferente, para isso, interfere no cotidiano da escola e em aspectos da cultura escolar, historicamente marcados por relações étnico-raciais excludentes e discriminatórias (XAVIER; DORNELLES, 2009, p. 583).

Esta normativa sobre os conteúdos não se refere ao desenvolvimento de uma disciplina escolar nova, ou que estes conteúdos devam se restringir às disciplinas de Educação Artística, Literatura ou História, mas que os mesmos devem fazer parte de todas as disciplinas que compõem o currículo da Educação Básica. Neste sentido, referente à disciplina de Sociologia, podemos dizer que os conteúdos tornados obrigatórios visam incorporar a justa participação dos povos indígenas, africanos e afrobrasileiros na formação da população brasileira (BRASIL, 2008), resgatando as suas contribuições nas áreas social, econômica e política, pertinentes à história do Brasil (BRASIL, 2008), propondo uma perspectiva de educação antirracista e rompendo com a percepção eurocêntrica do conhecimento (GOMES, 2004).

A alteração na LDB (Lei nº 9.394/1996) pela Lei n 10.639/2003 é seguida pela elaboração e instituição das Diretrizes Curriculares Nacionais para a Educação das Relações Étnico-Raciais e para o Ensino de História e Cultura Afro-Brasileira e 
Africana (Resolução CNE/CP $n^{\circ}$ 01/2004), tendo parecer favorável do Conselho Nacional de Educação (Parecer CNE/CP nº 003/2004), pois tais conteúdos propõem a reeducação sobre as relações étnico-raciais brasileiras mediante a divulgação e produção de conhecimentos, a formação de atitudes, posturas e valores que eduquem cidadãos orgulhosos de seu pertencimento étnico-racial (BRASIL, 2004).

O Parecer CNE/CP n ${ }^{\circ}$ 003/2004 indica que o ensino de história e cultura africana e afro-brasileira seja norteado pelos seguintes princípios: consciência política e histórica da diversidade; fortalecimento de identidades e de direitos e ações educativas de combate ao racismo e a discriminações (BRASIL, 2004). A partir desses pressupostos podemos observar as seguintes temáticas que norteiam o Parecer (2004): Educação das Relações Étnico-Raciais; História da África; História Brasileira O Negro na Formação da Sociedade Brasileira e Cultura Africana e Afro-Brasileira, enquanto possíveis conteúdos a serem abordados de forma independente pelas disciplinas e/ou de forma interdisciplinar.

No que tange que as Diretrizes Curriculares Nacionais para a Educação das Relações Étnico-Raciais e para o Ensino de História e Cultura Afro-Brasileira e Africana (BRASIL, 2004) ao abordar os objetivos da Educação das Relações étnicoraciais e do Ensino de História e Cultura Africana e Afro-Brasileira, pontuam que os mesmos não constituem responsabilidade apenas das escolas, mas, um trabalho conjunto do sistema de ensino e da sociedade, por isso, a participação de:

Art. $5^{\circ}[\ldots]$ grupos do Movimento Negro, grupos culturais negros, instituições formadoras de professores, núcleos de estudos e pesquisas, como os Núcleos de Estudos Afro-Brasileiros, com a finalidade de buscar subsídios e trocar experiências para planos institucionais, planos pedagógicos e projetos de ensino. (BRASIL, 2004, p. 20).

O que nos leva a pontuar um dos vetos que a Lei $n^{\circ}$ 10.639/2003 sofreu para o estabelecimento de sua aprovação, referente à participação da sociedade na formação continuada aos professores e professoras. Vejamos:

O primeiro deles [veto] exclui o artigo que estabelecia a obrigatoriedade das disciplinas História do Brasil e Educação Artística dedicarem, no ensino médio, o percentual de pelo menos $10 \%$ de seu conteúdo programático à temática história e cultura afro-brasileira [...] O segundo veto [...] retirou do texto o artigo que dispunha sobre a participação de entidades do movimento afro-brasileiro, de universidades e outras instituições de pesquisa relacionadas à história e cultura afro-brasileira, na oferta decursos de capacitação para professores [...]. (XAVIER; DORNELLES, 2009, p. 575). 
Apesar dos vetos, as Diretrizes Curriculares Nacionais para a Educação das Relações Étnico-Raciais e para o Ensino de História e Cultura Afro-Brasileira e Africana (2004) indicam a importância da participação de agentes externos, ao apresentarem aos estudantes e comunidade escolar conhecimentos diversos que são produzidos e transmitidos pelos sujeitos sociais, até então invisibilizados pela perspectiva eurocêntrica de saber (QUIJANO, 2005). Por outro lado, contribui com a valorização e reconhecimento destes sujeitos portadores de saberes não oficiais ao aproximar escola e a comunidade onde está inserida.

Lembrando que a inserção dos conteúdos curriculares referentes à história e à cultura africana e afro-brasileira visa à desconstrução de preconceitos, tanto na seleção de conteúdos, quanto em sua realização em sala de aula, na interação estudante e professor e daquele com os colegas de sala. Pois, não podemos perder de vista que,

\footnotetext{
embora as conquistas no plano legal tenham coibido manifestações de racismo, no plano real elas são insuficientes para criar as condições de possibilidade de acesso dos negros à riqueza produzida socialmente. Instrumentalizar a sociedade e a escola para o enfrentamento da questão racial é medida urgente e necessária [...]. (XAVIER; DORNELLES, 2009, p. 578).
}

Deste modo, devemos interrogar as práticas escolares e ampliar nossa capacidade de pensar o papel da educação (XAVIER; DORNELES, 2009, p. 584), o que se propõe a realizar a partir da identificação de como os conteúdos exigidos pela Lei ${ }^{\circ} 10.639 / 2003$ estão sendo abordados nos livros didáticos de Sociologia, aprovados pelo Edital do PNLD 2018.

\section{PNLD 2018: os livros didáticos de Sociologia}

O Edital do Programa Nacional do Livro Didático 2018 foi publicado em dezembro de 2015 (Edital de Convocação no 04/2015). O mesmo é identificado com o ano de referência de 2018, por ser o início do triênio de uso do livro didático destinado ao Ensino Médio. Devemos lembrar que o Programa em 2017 sofreu alterações a partir do Decreto $\mathrm{n}^{\circ}$ 9.099, dentre os quais se torna Programa Nacional do Livro e do Material Didático, mantendo as mesmas siglas, entretanto, como o Edital e os livros analisados aqui não foram tocados pelo Decreto, manteremos a menção ao PNLD na condição de Programa Nacional do Livro Didático. 
Sendo assim, o Edital 2018 aponta critérios a serem observados e cumpridos pelas editoras ao submeter uma obra, passando por duas etapas de avaliação. Na préanálise, são observados elementos da estrutura editorial e especificações técnicas. $\mathrm{Na}$ segunda etapa, a avaliação pedagógica, é realizada por professores e professoras da área, os mesmos são selecionados a partir da inscrição no Sistema Integrado de Monitoramento, Execução e Controle do MEC (Simec), na categoria livros, a partir dos critérios apontados pelo Edital de inscrição e seleção dos avaliadores.

No Edital PNLD 2018 são indicadas normatizações que devem ser observadas por autores e autoras e editoras na elaboração dos livros didáticos, no que tange aos seus conteúdos, frisamos as seguintes:

Lei ${ }^{\circ}$ 10.639/2003 - obrigatoriedade da temática História e Cultura AfroBrasileirall.

Lei $\mathrm{n}^{\circ} 11.645 / 2008$ obrigatoriedade da temática História e Cultura AfroBrasileira e Indígenall.

Lei $\mathrm{n}^{\circ} 11.684 / 2008$ inclui a Filosofia e a Sociologia como disciplinas obrigatórias nos currículos do Ensino Médio.

Diretrizes Curriculares Nacionais para o Ensino Médio, Resolução nº 2, de 30 de janeiro de 2012 e Parecer CNE/CEB n ${ }^{\circ}$ 5/2011.

Parecer CNE/CP no 3, 10/03/2004 e Resolução CNE/CP n ${ }^{\circ} 01$ de 17/06/2004 Aborda assunto relativo às Diretrizes Curriculares Nacionais para a Educação das Relações Étnico-Raciais e para o Ensino de História e Cultura AfroBrasileira e Africana. (BRASIL, 2015, p. 33).

$\mathrm{Na}$ segunda etapa da avaliação, a avaliação pedagógica, ficou a cargo de universidades, por exemplo, no caso do PNLD 2012 a instituição responsável pela avaliação foi a Universidade Federal do Rio de Janeiro (UFRJ), sob coordenação de Profa. Dra. Mariane Campelo Koslinsky (UFRJ), no Edital de 2015, a instituição responsável pela avaliação foi a Universidade Federal do Paraná (UFPR), sob a coordenação de Profa. Dra. Maria Tarcisa Silva Bega (UFPR. E no Edital de 2018 a instituição responsável foi a Universidade Estadual de Campinas (UNICAMP), sob responsabilidade do Prof. Dr. Michel Nicolau Netto, compondo a comissão técnica a Profa. Dra. Anita Handfas (UFRJ) e coordenação pedagógica com o Prof. Dr. Sávio Machado Cavalcante (UNICAMP).

A partir dos Guias dos Livros Didáticos de Sociologia, observamos a escolha pela aprovação de uma quantidade menor de livros didáticos por parte da avaliação pedagógica, se compararmos com a quantidade de obras aprovadas por outras disciplinas que participaram do processo de seleção e compra dos livros didáticos, vejamos: 
Quadro 1. Quantidade de obras aprovadas na avaliação pedagógica por disciplina de acordo com o Edital PNLD

\begin{tabular}{|l|l|c|c|c|}
\hline \multicolumn{2}{|c|}{ Disciplinas } & PNLD 2012 & PNLD 2015 & PNLD 2018 \\
\hline \multirow{2}{*}{ História } & Avaliadas & 24 obras & 21 obras & sem inform. \\
\cline { 2 - 5 } & Aprovadas & 19 obras & 19 obras & 13 obras \\
\hline \multirow{2}{*}{ Geografia } & Avaliadas & 18 obras & 20 obras & sem inform. \\
\cline { 2 - 5 } & Aprovadas & 14 obras & 18 obras & 14 obras \\
\hline \multirow{3}{*}{ Filosofia } & Avaliadas & 15 obras & 13 obras & sem inform. \\
\cline { 2 - 5 } & Aprovadas & 3 obras & 5 obras & 8 obras \\
\hline \multirow{2}{*}{ Sociologia } & Avaliadas & 14 obras & 13 obras & 12 obras \\
\cline { 2 - 5 } & Aprovadas & 2 obras & 6 obras & 5 obras \\
\hline
\end{tabular}

Fonte: Dados obtidos a partir do Guia de Livros Didáticos das disciplinas de História, Geografia, Filosofia e Sociologia referente aos PNLD 2012, PNLD 2015 e PNLD 2018.

A partir dos números indicados, podemos observar a variedade de materiais e possibilidades disponíveis à seleção por parte dos professores, neste sentido, frisamos, os títulos aprovados nos três processos de seleção do PNLD de Sociologia: 2012 (triênio 2012, 2013 e 2014) - Sociologia para o Ensino Médio e Tempos Modernos, tempos de Sociologia; 2015 (triênio 2015, 2016 e 2017) - Sociologia em Movimento; Sociologia Hoje; Sociologia para o Ensino Médio; Tempos Modernos, Tempos de Sociologia; Sociologia e Sociologia para Jovens do Século XXI; (triênio 2018, 2019 e 2020) - Sociologia em Movimento; Sociologia Hoje; Tempos Modernos, Tempos de Sociologia; Sociologia e Sociologia para Jovens do Século XXI.

\section{Nos restringindo aos conteúdos}

Ao refletir sobre a religião, em especial, as religiões de matriz africana, nos voltamos à relação entre o conhecimento científico, expresso pelo saber sociológico, e o de senso comum, expresso nas práticas e concepções de mundo, bem como a uma socialização preconceituosa frente às religiões de matriz africana, candomblé e umbanda, onde 


\begin{abstract}
O preconceito torna-se então uma postura, uma concepção, pela qual algumas pessoas consideram sua cultura, suas crenças, seus símbolos, superiores e/ou melhores do que os de outros povos e de outras culturas (etnocentrismo), servindo-se assim de avaliações negativas sobre as pessoas, suas culturas, seu imaginário simbólico, suas crenças e o seu ethos, isto é seu modo de ser no mundo. (OLIVEIRA, 2004, p.160 apud VIEIRA, 2016, p. 22).
\end{abstract}

Neste sentido, a disciplina de Sociologia vem desenvolver o processo de desnaturalização frente à identificação dos conhecimentos prévios dos alunos sobre estas religiões, ao frisar os elementos que compõem nossa diversidade religiosa. Constituindo um momento em que a capacidade de mediação do professor e da professora será testada, ao partir do senso comum e da realidade vivenciada pelos estudantes, para acessarem o saber sociológico, frente as religiões de matriz africana, entendendo, a relação entre ciência e senso comum, e, religião e ciência.

As religiões de matriz africana, neste caso o candomblé, expressa uma história nacional marcada pelo trabalho escravo, possui relação com o meio ambiente que denota a força da natureza em seus ritos representada pelos orixás e sua manutenção, e sua reprodução e manutenção se dá por meio da tradição oral (VIEIRA, 2016, p. 22-23). Por outro lado, a umbanda é uma religião originada no ambiente urbano, e ao afirmar "sua consciência de brasilidade, ela quer ser brasileira, esta ruptura precisa ser interpretada não como ausência do que é negro na estrutura umbandista, porém a África deixa de ser [a única] fonte de inspiração sagrada" (VIEIRA, 2016, p. 28), fazendo com que a umbanda tenha "em suas características a forma brasileira de ser, envolvendo arquétipos que constituem o povo brasileiro tais como o indígena e o negro" (VIEIRA, 2016, p. 28). Assim, se para o candomblé o sincretismo constituiu um mecanismo de segurança, para a umbanda, significou a síntese da complexidade da cultura brasileira ao fundir em um único corpo religioso "crenças, rituais, símbolos, imagens e mitos" (VIEIRA, 2016, p. 28) de diferentes fontes religiosas.

Assim, no que tange aos livros didáticos de Sociologia aprovados pelo PNLD 2018, identificamos que o tema religião foi inserido por três obras, sendo elas: Sociologia para jovens do século XXI; Tempos modernos, tempos de Sociologia e Sociologia. Observamos inicialmente, que a temática é abordada de dois modos, no âmbito do processo de socialização e enquanto objeto de estudo da Sociologia.

De forma geral, em Sociologia para jovens do século XXI, a religião é abordada em dois momentos, no capítulo três "O que se vê mais, o jogo ou o jogador?" Indivíduos e instituições sociais e no capítulo vinte "A gente não quer só comida..." 
Religiosidade e juventude no século XXI. No tocante as religiões de matriz africana, identificamos que ao abordar a religião enquanto agente de socialização, somos informados sobre o debate de seitas ou religiões, ou seja, como defini-las e diferenciálas, na sequência somos informados que o senso comum, tende a enquadrar as religiões de matriz africana na condição de seita, vejamos:

Há opiniões de senso comum em que se costuma dizer que o candomblé, o espiritismo e a umbanda são seitas. Entretanto, se observarmos a História do Brasil, veremos que estas manifestações religiosas são bem estáveis e permanentes. Os primeiros terreiros de candomblés surgem no início do século XIX. O espiritismo chega ao Brasil no final do século XIX e se mantém como instituição até os dias de hoje. A umbanda surge nos primeiros anos do século XX, no Rio de Janeiro, e está presente em todo o Brasil atualmente [...]. (OLIVEIRA; COSTA, 2016, p. 45).

Continuando a leitura, nos é indicado que há formas distintas das religiões se expressarem, mesmo assim, continuam sendo religiões, assim:

[...] É claro que estas religiões não têm uma organização centralizada, como a Igreja Católica. No entanto, elas apresentam hierarquias e rituais permanentes e a participação de seus membros nos cultos acontece de forma bastante coesa. (OLIVEIRA; COSTA, 2016, p. 45).

Passando para o vigésimo capítulo, observamos a religião como objeto de estudo da Sociologia, e ao abordar as religiões no Brasil, especificamente, o candomblé e a umbanda, somos informado sobre o surgimento delas, frisando a longevidade da primeira, desenvolvida concomitante a inserção do trabalho escravo de africanos no novo território português, constituindo um mecanismo de conservação do sentimento de comunidade e a transmissão da cultura (p. 309).

Durante o cativeiro, uma das únicas coisas que não se pôde roubar ao africano escravizado foi a fé religiosa. E essa fé foi sempre um fator de reconstrução de suas culturas. Assim, a religião impregnou todas as atividades negras brasileiras influenciando até sua vida profana [...]. (OLIVEIRA; COSTA, 2016, p. 309).

Na sequência somos informados sobre o culto aos orixás e aos antepassados, o que nos leva ao surgimento da umbanda no final do século XIX, no Rio de Janeiro, sendo frisado o sincretismo da religião, caracterizada pelo culto aos antepassados, e aos orixás o candomblé, como podemos observar na citação abaixo: 


\begin{abstract}
Além dos orixás, entidades divinas, poderes e patronos de forças da natureza, Exu, Yemanjá, Oxum, Oxossi, Xangô, Iansã, Oxumaré e outros, os africanos e seus descendentes sempre cultuaram também os antepassados, os eguns aqueles espíritos de indivíduos que depois se converteram em ancestrais, em "pais" (Baba Egun) [...].

Enquanto o candomblé cultua as forças da natureza, chamadas de orixás, a umbanda pratica o culto de diversos espíritos ancestrais, chamadas de entidades, como pretos-velhos, caboclos, exus e crianças. Esses espíritos incorporam em seus fiéis - adeptos iniciados ritualmente na umbanda — pra dar consultas de ajuda e prestar caridade à comunidade. A umbanda é uma criação essencialmente brasileira, surgida na primeira década do século XX, no Rio de Janeiro. É um culto chamado de sincrético, pois há uma certa mistura de cultos africanos aos ancestrais, culto aos ancestrais indígenas e há também símbolos católicos [...]. (OLIVEIRA; COSTA, 2016, p. 309).
\end{abstract}

Passando para o próximo livro, Tempos modernos, tempos de Sociologia, o tema da religião é abordado no capítulo dezesseis sob o título O Brasil ainda é um país católico?

A pergunta título orienta a organização do conteúdo apresentado, e se conclui que apesar do aumento das religiões adotadas pelos brasileiros, ainda somos um país católico, assim, neste movimento observamos, também, a migração de adeptos para outras religiões, dentre as quais, o candomblé e a umbanda. Religiões que passaram a ser identificadas nominalmente a partir de 1991 por parte do IBGE (Instituto Brasileiro de Geografia e Estatística) pois até então elas eram registradas na opção "outras religiões".

Como as pesquisas demonstram, houve recentemente uma alteração na composição religiosa da população brasileira. Ainda que a religião católica continue sendo a primeira, outras crenças vê ganhando espaço [...]. (BOMENY; FREIRE-MEDEIROS; O’DONNELL, 2016, p. 252).

[...] Depois que o IBGE, em 1991, decidiu colher separadamente os dados da umbanda e do candomblé, foi possível perceber que também aqui houve migração. O sociólogo Antonio Flávio Pierucci mostra que a umbanda passou de 541 mil seguidores em 1991 para 432 mil em 2000, ou seja, perdeu mais de 100 mil adeptos, enquanto o candomblé teve um acréscimo de 33 mil adeptos no mesmo período. (BOMENY; FREIRE-MEDEIROS; O’DONNELL, 2016, p. 253).

No caso da umbanda, somos informados sobre o peso do sincretismo em sua constituição, sendo uma religião marcadamente urbana que surge no final do século XIX.

[...] A umbanda surgiu em 1917, em Niterói, Rio de Janeiro, por meio da união de elementos africanos, indígenas, católicos e espíritas. Por esse motivo, na década de 1920 diversos intelectuais passaram a considera-la a melhor expressão popular do sincretismo religioso praticado no país. Alguns 
estudiosos a valorizavam por ser uma crença adaptada ao jeito de ser não dos negros mas de todas as outras etnias que compunham sociedade brasileira [...]. (BOMENY; FREIRE-MEDEIROS; O’DONNELL, 2016, p. 253).

Em Sociologia, a religião é abordada no capítulo sete sob o título Sociedade e religião onde há menção as religiões de matriz africana, mas a mesma ocorre em box fora do texto central do capítulo, sendo apresentado enquanto recorte de jornal e atividade. Por meio de uma notícia referente a ações desenvolvidas pela Fundação Palmares em consequência do Dia Internacional de Combate à Intolerância Religiosa (21 de janeiro): "Dia Nacional de Combate à Intolerância religiosa - Com apoio da Fundação Cultural Palmares, Comissão de Combate à Intolerância Religiosa lança livro e DVD sobre o tema [...]" (BOMENY; FREIRE-MEDEIROS; O’DONNELL, 2016, p. 202).

Na sequência, há atividade reflexiva sobre um caso de intolerância religiosa ocorrido em 2015, onde uma criança foi agredida com uma pedrada na saída do culto, a atividade é relacionada a uma citação de artigos da Declaração dos Direitos Humanos sobe a liberdade de expressão religiosa enquanto direito.

Menina vítima de intolerância religiosa diz que vai ser difícil esquecer pedrada

$[\ldots]$.

A garota foi agredida no último domingo (14) e, segundo a avó, que é mãe de santo, todos estavam vestidos de branco, porque tinham acabado de sair do culto. Eles caminhavam para casa, na Vila da Penha, quando dois homens começaram a insultar o grupo. Um deles jogou uma pedra, que bateu num poste e depois atingiu a menina.

[...].

Na delegacia, o caso foi registrado como preconceito de raça, cor, etnia ou religião e também com lesão corporal, provocada por pedra. Os agressores fugiram num ônibus que passava [...].

1. Em que consiste um fenômeno de intolerância religiosa?

2. Como esse fato narrado na notícia acima fere a Constituição Federal da República Federativa do Brasil e a Declaração Universal dos Direitos Humanos? (BOMENY; FREIRE-MEDEIROS; O'DONNELL, 2016, p. 203).

A partir do exposto, entendemos que a definição de conteúdo não é algo simples no âmbito da Sociologia, o que foi possível identificar pelos livros didáticos, onde, dentro das cinco obras aprovadas pelo PNLD 2018, três delas abordam o tema das religiões de matriz africana. Observamos que ao falar da religiosidade, os livros didáticos de Sociologia escolheram não apresentar os princípios das religiões de matriz 
africana, por outro lado, informaram sua origem e a importância do sincretismo para sua constituição, apesar de não explicarem o que seria sincretismo religioso. O que permite apontarmos que a religião ainda é um tema delicado, principalmente inserida no contexto da história e cultura africana e afro-brasileira, neste sentido, frisamos a questão da intolerância religiosa, um elemento a ser considerado no campo da multiplicidade religiosa em que estamos inseridos, e que foi abordado por um dos livros.

Ao nos deter sobre a história e cultura africana e afro-brasileira, entendemos que a abordagem desta temática objetiva a reflexão das nossas relações étnico-raciais, e como consequência, constitui um mecanismo de combate ao racismo. Podemos observar que nas obras indicadas a abordagem do tema levou ao debate da intolerância religiosa em apenas uma das obras, nas outras, o debate se deu no âmbito do sincretismo religioso e na origem das religiões. O que nos faz pensar na formação dos professores e professoras ao abordarem este tema, pois, tal conteúdo suscita dúvidas e preconceitos, tanto por parte dos educadores e educadoras, quanto dos estudantes. A história e cultura africana constituem disciplinas obrigatórias nos cursos de licenciatura? As formações continuadas para professores e professoras abordam as religiões de matriz africana e afro-brasileira? Nossos profissionais da educação sabem lidar com o racismo no ambiente escolar? Como nossos estudantes adeptos do candomblé e umbanda são recebidos no ambiente escolar?

Por isso, a importância da comunidade em que a escola está inserida ser chamada para participar e ocupar o espaço escolar, como apontado pelas Diretrizes Curriculares Nacionais para a Educação das Relações Étnico-Raciais e para o Ensino de História e Cultura Afro-Brasileira e Africana, onde a corresponsabilidade entre escola e sociedade é necessária para o desenvolvimento de educação antirracista, reconhecendo outros sujeitos portadores de saberes e a valorização de sua fala, ao se apropriar e ocupar o lugar de fala que nos pertence ${ }^{2}$.

\footnotetext{
${ }^{2}$ Ao citarmos o lugar de fala do negro, o fazemos no sentindo de reconhecermos a existência de múltiplas epistemologias, o que leva a identificação e reconhecimento de diversos sujeitos portadores de uma vivência e saberes que devem ser reconhecidos, e neste sentido ouvidos para assim rompermos com um discurso universal e homogeneizante. Neste sentido, não estamos falando de trajetórias individuais, mas de sujeitos inseridos em um grupo com uma história invisibilizada, o que tem consequências no seu acesso aos seus direitos de forma plena. Deste modo, como apontado por Djamila Ribeiro (2017, p. 3940), "O lugar social não determina uma consciência discursiva sobre esse lugar. Porém, o lugar que ocupamos socialmente nos faz ter experiências distintas e outras perspectivas", assim, "Ao promover uma multiplicidade de vozes o que se quer, acima de tudo, é quebrar com o discurso autorizado e único, que se pretende universal” (RIBEIRO, 2017, p. 40). RIBEIRO, Djamila. O que é: lugar de fala? Belo Horizonte, MG: Letramento, Justificando, 2017.
} 
Neste sentido, Quijano (2009) nos alerta que os saberes apresentam limites e que estes devem ser reconhecidos, o que pode levar à atuação conjunta de diversas epistemologias para a solução de determinado problema. Neste caso, nosso problema constitui o desenvolvimento de uma educação com pauta antirracista, a partir do reconhecimento e identificação de todos os envolvidos na formação de nossa sociedade, uma sociedade multicultural e pluriétnica, superando a simplificação e apagamento proporcionado pela perspectiva de miscigenação.

\section{Considerações finais}

Ao reconhecer o avanço do conservadorismo atinge significativamente a identificação e o reconhecimento de outros sujeitos portadores de saberes, nos preocupamos com o risco para o debate sobre o racismo, por exemplo, a partir dos efeitos da intolerância religiosa. Pois, apesar da inserção dos conteúdos de história e cultura africana e afro-brasileira por parte dos livros didáticos, salientamos a fuga ou desconforto em lidar com o racismo e suas origens, consequentemente a problematização das relações étnico-raciais em prol de um educação antirracista.

Há muito ainda a ser feito para a inserção da história e cultura africana e afrobrasileira no âmbito escolar, consequentemente, o rompimento da perspectiva eurocêntrica de saberes que limita ou mesmo impede o reconhecimento e o movimento de fala dos afro-brasileiros no espaço de saber que constitui a escola. Pois, para o desenvolvimento destas temáticas, devemos iniciar a refletir nossas relações étnicoraciais, ao identificar que a intolerância religiosa é mais uma faceta do nosso racismo.

\section{Referências}

BARDIN, Laurence. Análise de conteúdo. $3^{\text {a }}$ ed. Lisboa, Portugal: Edições 70, 2004.

BRASIL. Decreto no 16.782-A, de 13 de janeiro de 1925. Estabelece o concurso da União para a diffusão do ensino primario, organiza o Departamento Nacional do Ensino, reforma o ensino secundario e o superior e dá outras providencias. Disponível em: http://www.planalto.gov.br/ccivil_03/decreto/1910-1929/d16782a.htm Acesso em: 06 jan. 2020.

Decreto no 9.099, de 18 de julho de 2017. Dispõe sobre o Programa Nacional do Livro e do Material Didático. Disponível em: http://www.planalto.gov.br/ccivil_03/_ato2015-2018/2017/decreto/D9099.htmAcesso em: 06 jan. 2020. 
Decreto n⿳0 981, de 8 de Novembro de 1890. Approva o Regulamento da Instrucção Primaria e Secundaria do Districto Federal. Disponível em: https://www2.camara.leg.br/legin/fed/decret/1824-1899/decreto-981-8-novembro-1890515376-publicacaooriginal-1-pe.html Acesso em: 06 dez. 2019.

. Decreto-Lei no 1.006, de 30 de Dezembro de 1938. Estabelece as condições de produção, importação e utilização do livro didático. Disponível em: https://www2.camara.leg.br/legin/fed/declei/1930-1939/decreto-lei-1006-30-dezembro1938-350741-publicacaooriginal-1-pe.html Acesso em: 06 dez 2019.

Decreto-Lei no 4.244, de 9 de abril de 1942. Lei orgânica do ensino secundário. Disponível em: http://www.planalto.gov.br/ccivil_03/Decreto-Lei/19371946/Del4244.htm Acesso em: 20 dez. 2019.

Edital de Convocação 04/2015 - CGPLI. Edital de Convocação para o Processo de Inscrição e Avaliação de Obras Didáticas para o Programa Nacional do Livro Didático PNLD 2018. Disponível em: http://portal.mec.gov.br/index.php?option=com_docman\&view=download\&alias $=3956$ 1-pnld-2018-edital-pdf\&Itemid=30192 Acesso em: 23 mar. 2019.

Guia dos livros didáticos: PNLD 2012 - Geografia. Brasília: Ministério da Educação, Secretaria de Educação Básica, 2011.

Guia dos livros didáticos: PNLD 2012 - História. Brasília: Ministério da Educação, Secretaria de Educação Básica, 2011.

Guia dos livros didáticos: PNLD 2012 - Sociologia. Brasília: Ministério da Educação, Secretaria de Educação Básica, 2011.

Guia dos livros didáticos: PNLD 2012- Filosofia. Brasília: Ministério da Educação, Secretaria de Educação Básica, 2011.

Guia dos livros didáticos: PNLD 2015 - Geografia. Brasília: Ministério da Educação, Secretaria de Educação Básica, 2014.

Guia dos livros didáticos: PNLD 2015 - História. Brasília: Ministério da Educação, Secretaria de Educação Básica, 2014.

Guia dos livros didáticos: PNLD 2015- Filosofia. Brasília: Ministério da Educação, Secretaria de Educação Básica, 2014.

Guia dos livros didáticos: PNLD 2015- Sociologia. Brasília: Ministério da Educação, Secretaria de Educação Básica, 2014.

Lei $\mathbf{n}^{\mathbf{0}} \mathbf{1 0 . 6 3 9}$, de 9 de janeiro de 2003. Altera a Lei $\mathrm{n}^{\circ} 9.394$, de 20 de dezembro de 1996, que estabelece as diretrizes e bases da educação nacional, para incluir no currículo oficial da Rede de Ensino a obrigatoriedade da temática "História e Cultura Afro-Brasileira", e dá outras providências. Disponível em: http://www.planalto.gov.br/ccivil_03/leis/2003/110.639.htm Acesso em: 22 jan. 2020.

Lei $\mathbf{n}^{\mathbf{0}}$ 11.645, de 10 março de 2008. Altera a Lei $\mathrm{n}^{\circ}$ 9.394, de 20 de dezembro de 1996, modificada pela Lei $\mathrm{n}^{\circ} 10.639$, de 9 de janeiro de 2003, que estabelece as 
diretrizes e bases da educação nacional, para incluir no currículo oficial da rede de ensino a obrigatoriedade da temática "História e Cultura Afro-Brasileira e Indígena". Disponível em: http://www.planalto.gov.br/ccivil_03/_Ato20072010/2008/Lei/L11645.htm Acesso em: 22 jan. 2020.

Lei $\mathbf{n}^{\circ}$ 11.684, de 2 de junho de 2008. Altera o art. 36 da Lei no 9.394, de 20 de dezembro de 1996, que estabelece as diretrizes e bases da educação nacional, para incluir a Filosofia e a Sociologia como disciplinas obrigatórias nos currículos do ensino médio. Disponível em: http://www.planalto.gov.br/ccivil_03/_Ato20072010/2008/Lei/L11684.htm\#: :text=LEI\%20N\%C2\%BA\%2011.684\%2C\%20DE\%202, nos\%20curr\%C3\%ADculos\%20do\%20ensino\%20m\%C3\%A9dio Acesso em: 22 jan. 2020.

Lei $\mathbf{n}^{\mathbf{0}} \mathbf{1 3 . 4 1 5}$, de 16 de fevereiro de 2017. Altera as Leis $\mathrm{n}^{\circ}$ 9.394, de 20 de dezembro de 1996, que estabelece as diretrizes e bases da educação nacional, e 11.494, de 20 de junho 2007, que regulamenta o Fundo de Manutenção e Desenvolvimento da Educação Básica e de Valorização dos Profissionais da Educação, a Consolidação das Leis do Trabalho - CLT, aprovada pelo Decreto-Lei $\mathrm{n}^{\circ} 5.452$, de $1^{\circ}$ de maio de 1943 , e o Decreto-Lei $\mathrm{n}^{\circ} 236$, de 28 de fevereiro de 1967; revoga a Lei ${ }^{\circ} 11.161$, de 5 de agosto de 2005; e institui a Política de Fomento à Implementação de Escolas de Ensino Médio em Tempo Integral. Disponível em: http://www.planalto.gov.br/ccivil_03/_ato20152018/2017/lei/113415.htm Acesso em: 22 jan. 2020.

Lei no 9.394, de 20 de dezembro de 1996. Estabelece as diretrizes e bases da educação nacional. Disponível em: http://www.planalto.gov.br/ccivil_03/leis/19394.htm. Acesso em: 20 fev. 2020.

Medida Provisória no 746, de 22 de setembro de 2016. Institui a Política de Fomento à Implementação de Escolas de Ensino Médio em Tempo Integral, altera a Lei n ${ }^{\circ} 9.394$, de 20 de dezembro de 1996, que estabelece as diretrizes e bases da educação nacional, e a Lei n ${ }^{\circ} 11.494$ de 20 de junho 2007, que regulamenta o Fundo de Manutenção e Desenvolvimento da Educação Básica e de Valorização dos Profissionais da Educação, e dá outras providências. Disponível em: http://www.planalto.gov.br/ccivil_03/_ato2015-2018/2016/mpv/mpv746.htm 06 jan. 2020.

Ministério da Educação. PNLD 2018: Filosofia, Guia de Livros Didáticos Ensino Médio. Brasília, DF: Ministério da Educação, Secretária de Educação Básica, 2017.

Ministério da Educação. PNLD 2018: História, Guia de Livros Didáticos Ensino Médio. Brasília, DF: Ministério da Educação, Secretária de Educação Básica, 2017.

Ministério da Educação. PNLD 2018: Sociologia, Guia de Livros Didáticos Ensino Médio. Brasília, DF: Ministério da Educação, Secretária de Educação Básica, 2017.

Parecer CNE/CP n⿳0 003, 10 de março de 2004. Institui Diretrizes Curriculares Nacionais para a Educação das Relações Étnico-Raciais e para o Ensino de História e 
Cultura Afro-Brasileira e Africana. Disponível em:

http://portal.mec.gov.br/cne/arquivos/pdf/res012004.pdf. Acesso em: 06 mar. 2019.

Resolução no 1, de 17 de junho de 2004. Institui Diretrizes Curriculares

Nacionais para a Educação das Relações Étnico-Raciais e para o Ensino de História e Cultura Afro-Brasileira e Africana. Disponível em:

http://portal.mec.gov.br/cne/arquivos/pdf/res012004.pdf 06 jan. 2020.

ENGEROFF, Ana Martina Baron. Mapeando a produção sobre o livro didático de Sociologia: um estado da arte no campo acadêmico brasileiro. 110f. Trabalho de Conclusão de Curso (Graduação em Ciências Sociais) - Universidade Federal de Santa Catarina, Florianópolis, SC, 2017.

FREIRE-MEDEIROS, Bianca; BOMENY, Helena; O'DONNEL, Julia; EMERIQUE, Raquel Balmant. Tempos modernos, tempos de sociologia. São Paulo: Editora do Brasil, 2016. 3 ed.

GOMES, Nilma Lino. Educação e relações raciais: refletindo sobre algumas estratégias de atuação. In: MUNANGA, Kabengele (org.) Superando o racismo na escola. 2 ed. Brasília: Ministério da Educação, Secretaria de Educação Continuada, Alfabetização e Diversidade, 2004.

MEUCCI, Simone. A institucionalização da sociologia no Brasil: os primeiros manuais e cursos. 2000. Dissertação (Mestrado) - Universidade Estadual de Campinas, Instituto de Filosofia e Ciências Humanas, Campinas, SP, 2000.

MOTIM, Benilde Lenzi; BRIDI, Maria Aparecida; ARAÚJO, Silvia Maria de. Sociologia. São Paulo: Scipione, 2016. 2 ed.

OLIVEIRA, Luiz Fernandes de; COSTA, Ricardo Cesar Rocha. Sociologia para jovens do século XXI. Rio de Janeiro: Imperial, 2016. 4 ed.

OLIVEIRA, Sandra Regina Ferreira de; CAIMI, Flávia Eloisa. PNLD: memórias, tensões e desafios. Revista História Hoje, v. 7, n. 14, dez. 2018. p. 5-20. CAIMI, Flávia Eloisa. Sob nova direção: o PNLD e seus desafios frente aos contextos políticoeducativos emergentes. Revista História Hoje, v. 7, n. 14, p. 21-40, dez. 2018.

PEREIRA, Márcia Moreira; SILVA, Maurício. Percurso da Lei 10639/03: antecedentes e desdobramentos. Linguagens \& Cidadania, v. 14, jan./dez., 2012.

PEREZ, Ana Paula Lopes Bogas. As Equipes Multidisciplinares das Escolas Públicas do Paraná e suas ações para a efetivação da Lei federal no 10.639/2003. 2018. Dissertação (Mestrado em Ciências Sociais) - Universidade Estadual de Londrina, Londrina, 2018.

QUIJANO, Anibal. Colonialidade do poder, eurocentrismo e América Latina. In: A colonialidade do saber: eurocentrismo e ciências sociais. Perspectivas

Latino-Americanas. Argentina: CLACSO, Consejo Latinoamericano de Ciências Sociais, 2005. Disponível em: http://bibliotecavirtual.clacso.org.ar/clacso/sursur/20100624103322/12_Quijano.pdf Acesso em: 24 jan. 2019. 
RIBEIRO, Djamila. O que é: lugar de fala? Belo Horizonte, MG: Letramento, Justificando, 2017.

SAVIANI, Dermeval. A supervisão educacional em perspectiva histórica: da função à profissão pela mediação da idéia. In: FERREIRA, Naura Syria Carapeto (Org.).

Supervisão educacional para uma escola de qualidade: da formação à ação. São Paulo: Cortez, 1999.

VIEIRA, Maurício Benedito da Silva. Religiões brasileiras de matrizes africanas no contexto da Lei 10.639/03 e Cuiabá-MT. 2016. Dissertação (Mestrado em Educação) Universidade Federal de Mato Grosso, Cuiabá, 2016.

XAVIER, Maria do Carmo; DORNELLES, Ana Paula Lacerda. O debate parlamentar na tramitação da Lei 10.639/2003: interrogando o papel da escola na construção da identidade cultural e étnica no Brasil. EccoS - Revista Científica, São Paulo, v. 11, n. 2, jul./dez. 2009, p. 569-586. 